Experimental Research

\title{
Antibiotic susceptibilities of group B streptococci
}

\author{
Aziz Ramazan Dilek ${ }^{\mathrm{a} *}$, Hasan Kesbiç ${ }^{\mathrm{b}}$, Nursel Dilek ${ }^{\mathrm{b}}$ \\ ${ }^{a}$ Training and Research Hospital, Microbiology Laboratory, Rize, Turkey \\ ${ }^{b}$ Dr. I. Şevki Atasagun State Hospital, Nevşehir, Turkey
}

\begin{tabular}{|c|c|}
\hline \multicolumn{2}{|c|}{ ARTICLE INFO } \\
\hline \multicolumn{2}{|c|}{ Article History } \\
\hline Received & $22 / 12 / 2010$ \\
\hline Accepted & $23 / 12 / 2010$ \\
\hline \multicolumn{2}{|c|}{ * Correspondence to } \\
\hline \multicolumn{2}{|c|}{ Aziz Ramazan Dilek } \\
\hline \multicolumn{2}{|c|}{ Eğitim Araştırma Hastanesi, } \\
\hline \multicolumn{2}{|c|}{ Mikrobiyoloji Laboratuarı, Rize } \\
\hline e-mail:ar.c & hotmail.com \\
\hline
\end{tabular}

\section{Keywords:}

Streptococcus agalactiae

Group B streptococcus

Penicilin

Erythromycin

Tetracycline

Ciprofloxacin

\begin{abstract}
Streptococcus agalactiae is a frequent cause of serious infections in newborn babies. It has increasingly been recognized as a pathogen in nonpregnant adults. Penicillin and ampicillin are the drugs of choice for treatment of group B streptococcus (GBS) infections. Widespread use of these antibiotics has potentated the emergence of antibiotic resistance. Total 56 isolates included in the study were recovered from vaginal swabs and ürine samples. Isolates were tested for antimicrobial susceptibility by Kirby-Bauer disk diffusion susceptibility testing method. All of the 56 clinical isolates tested were fully susceptible to penicillin, ampicillin and cephalothin. Only $8(14.2 \%)$ and $6(10.7 \%)$ were resistant to erythromycin and clindamycin, respectively. All of the 56 clinical isolates were not susceptible to tetracycline.

J. Exp. Clin. Med., 2011; 28:1-3
\end{abstract}

\section{Introduction}

Streptococcus agalactiae or group B streptococcus (GBS) is a frequent cause of serious infections often associated with mortality and morbidity in newborn babies (Al-Sweih et al., 2005). In the 1990s, 4 to 6 percent of affected newborns died from the infection (Schrag et al., 2000). It has increasingly been recognized as a pathogen in nonpregnant adults, especially among patients with underlying conditions (Betriu et al., 2003). The incidence of group B streptococcal disease is also high in pregnant women and the elderly (Schrag et al., 2000). Penicillin and ampicillin are the drugs of choice for treatment of GBS infections, and clindamycin and erythromycin are the recommended alternatives for patients who are allergic to ß-lactam agents (Quiroga et al., 2008). Clindamycin and erythromycin resistance rates are 15-20\% and they are increasing worldwide (Ölçü and Eşel, 2007). Widespread use of these antibiotics in various clinical conditions has potentated the emergence of antibiotic resistance (Quiroga et al., 2008).

This study was performed to determine the susceptibility patterns of the Streptococcus agalactiae isolates to a variety of antibiotics.

\section{Material and Methods}

The 56 isolates, recovered from vaginal swab and ürine samples included in the study retrospectively. A total of 56 pa- tients included the study were aged 22 to 66 years.

The arithmetic mean, median age of patients were 38.50 and 38.00 , respectively. All isolates were identified by conventional methods as GBS. Isolates were tested for antimicrobial susceptibility to penicillin, ampicillin, cephalothin, clindamycin, ciprofloxacin, vancomycin, Trimethoprim/sulfamethoxazole, tetracycline, imipenem and erythromycin by Kirby-Bauer disk diffusion susceptibility testing method. Bacteria grown on blood agar (Oxoid, Basingstoke, UK) suspended in sterile saline to a $0.5 \mathrm{McF}$ arland turbidity standard as an inoculum containing $105 \mathrm{cfu} / \mathrm{ml}$. This was inoculated onto a Mueller-Hinton agar plate supplemented with $5 \%$ sheep blood, by streaking evenly with a swab. Then the plates were incubated in an aerobic incubator at $35^{\circ} \mathrm{C}$ for 24 $\mathrm{h}$. The zone sizes were then recorded for each antimicrobial agent and interpreted according to the Clinical and Laboratory Standards Institute (CLSI).

\section{Result}

A total of 56 GBS isolates were collected. All of the 56 clinical isolates tested were fully susceptible to penicillin, ampicillin and cephalothin. All of the 56 clinical isolates were not susceptible to tetracycline. Only $8(14.2 \%)$ and $6(10.7 \%)$ were resistant to erythromycin and clindamycin, respectively. Ciprofloxacin resistance rate was 3 (5.3\%). Results of antiobiotic susceptibility test was demonstrated in Table 1. 
Table 1: Antibiotic susceptibility profiles of group B streptococcus

\begin{tabular}{lccc}
\hline Antimicrobial agent & Susceptible & Intermediate & Resistant \\
\hline Penicillin & 100 & -- & -- \\
Ampicillin & 100 & -- & -- \\
Cephalothin & 100 & -- & -- \\
Imipenem & 100 & -- & -- \\
erythromycin & 85.7 & -- & 14.2 \\
clindamycin & 89.2 & -- & 10.7 \\
ciprofloxacin & 85.7 & 8.9 & 5.3 \\
vancomycin & 100 & -- & -- \\
Trimethoprim/sulfamethoxazole & 92.8 & 1.7 & 5.3 \\
tetracycline & -- & -- & 100 \\
\hline \hline Total: 56 isolates & & & \\
\hline
\end{tabular}

\section{Discussion}

Streptococcus agalactiae is one of the pathogens responsible for peripartum maternal and neonatal infections (De Mouy et al., 2001). The source of the organism in most of these cases maternal genital or gastrointestinal tract or both (Kulkarni et al., 2001). Transmission from mather to child has been reported to be 29 times higher in GBS-colonized mothers than in noncolonized mothers (Elbaradie et al., 2009). while the colonization rates of group B streptococcus in pregnant women have been reported range from $4 \%$ to $18.6 \%$ in various studies, (Karakus et al., 2007) a carrier rate of $31.6 \%$ was found in pregnant women in one area of Zimbabwe (Moyo et al., 2002). İn other study GBS colonization was found in 19 of 100 parturient women (Kraśnianin et al., 2009).

A Centers for Disease Control and Prevention (CDC) surveillance study estimated that the use of intrapartum chemoprophylaxis has prevented 4500 cases per year of GBS sepsis and 225 deaths per year in the United States (Money and Dobson, 2004). Penicillin is still the drug of choice for treatment of GBS infection and erythromycin is alternative to the penicillins in cases of intolerance. The increasing prevalence of macrolide resistance raises concern about the empirical use of these antibiotics for the prevention of GBS infections (Fluegge et al., 2004; Tünger et al., 2005). While aminopenicillins are still highly active against GBS in most susceptibility studies such as our study (Al-Sweih et al., 2005; Quiroga et al., 2008; De Mouy et al., 2001; Fluegge et al., 2004; Topkaya et al., 2003; Figueira-Coelho et al., 2004; Monique et al., 2006), resistance to erythromycin and clindamycin have been reported in many studies range from $0.7 \%$ to $21.4 \%$ for erythromycin and $1.7 \%$ to $17.5 \%$ for clindamycin (Betriu et al., 2003; Quiroga et al., 2008; Ölçü and Eşel, 2007; De Mouy et al., 2001; Fluegge et al., 2004; Topkaya et al., 2003; Figueira-Coelho et al., 2004). Compared to this studies which have been reported from our country and other countries, the rates of erythromycin and clindamycin resistance were concordant in our experience.

While Resistance to quinolones has been described recently for GBS, An increase in resistance of GBS to quinolones has been reported (Quiroga et al., 2008; Topkaya et al., 2003; Kawamura et al., 2003). Compared the study which has been reported from Argentina the rate of ciprofloxacin resistance is higher in our study (Quiroga et al., 2008).

While resistance to Trimethoprim/sulfamethoxazole have been reported range from $10.6 \%$ to $53.2 \%$, the rate of Trimethoprim/sulfamethoxazole resistance is lower in our study (De Mouy et al., 2001; Quiroga et al., 2008).

İn addition All of the 56 clinical isolates were Resistant to tetracycline. Reported rates of tetracycline resistance were range 29\% to 92.6 (Quiroga et al., 2008; Ölçü and Eşel, 2007; De Mouy et al., 2001; Topkaya et al.,2003).

With more widespread use of antibiotics, selection of antibiotic-resistant GBS may occur. We recommended that routine reporting of GBS susceptibilities should be performed to help guide the clinician in the choice of antibiotic therapy for invaziv GBS infections and eradication of colonization.

\section{REFERENCES}

Al-Sweih, N., Jamal, M., Kurdia, M., Abduljabar, R., Rotimi, V. 2005. Antibiotic susceptibility profile of group B streptococcus (streptococcusagalactiae ) at the Maternity Hospital, Kuwait. Med. Princ. Pract.14, 260-263.

Betriu, C., Culebras, E., Gomez, M., Rodríguez-Avial, I., Sanchez, B.A., Agreda, M.C., Picazo, J.J. 2003. Erythromycin and clindamycin resistance and telithromycin susceptibility in streptococcus agalactiae. Antimicrob. Agents Ch. 47, 1112-1114.

De Mouy, D., Cavallo, J.D., Leclercq, R., Fabre, R. The Aforcopi-B1o Network. 2001. Antibiotic susceptibility and mechanisms of erythromycin resistance in clinical 1solates of streptococcus agalactiae: french multicenter study. Antimicrob. Agents Ch. 45, 2400-2402.

Elbaradie, S.M.Y., Mahmoud, M., Farid, M. 2009. Maternal and neonatal screening for group B streptococci by SCPB gene based PCR: a pre liminary study. Indian J. Med. Microbi. 27, 17-21.

Figueira-Coelho, J., Ramirez, M., Salgado, M.J., Melo-Cristino, J. 2004. Streptococcus agalactiae in a large portuguese teaching hospital: antimicrobial susceptibility, serotype distribution, and clonal analysis of macrolide-resistant 1solates. Microb. Drug Resist. 10, 31-36.

Fluegge, K., Supper, S., Siedler, A., Berner, R. 2004. Antibiotic susceptibility in neonatal invasive isolates of streptococcus agalactiae in a 2-year nationwide surveillance study in Germany. Antimicrob. Agents Ch. 48, 4444-4446.

Karakus, M., Karaca, D.Y., Günçiner, Ş. 2007. Colonization and antimicrobial resistance patern of group B streptococcus in pregnant women. Ege J. Med. 46, $151-154$.

Kawamura, Y., Fujiwara, H., Mishima, N., Tanaka, Y., Tanimoto, A., Ikawa, S., Itoh Y., Ezaki, T. 2003. First streptococcus agalactiae isolates highly resistant to quinolones, with point mutations in gyrA and parC. Antimicrob. Agents Ch. 47, 3605-3609

Kraśnianin, E., Skret-Magierło, J., Witalis, J., Barnaś, E., Kluz, T., Kozieł, A., Skret, A. 2009. The incidence of streptococcus group b in 100 parturient women and the transmission of pathogens to the newborn. Ginekol. Pol. 80, 285-289.

Kulkarni, A.A., Pawar, S.G., Dharmadhikari, C.A., Kulkarni, R.D. 2001. Colonization of pregnant women and their newborn infants with group-B streptococci. Indian J. Med. Microbi. 19, 1-4.

Money, D.M., Dobson, S. 2004. The prevention of early-onset neonatal group B streptococcal disease. J. Obstet. Gynaecol. Can. 26, 826-832.

Monique, T.S., Jan, K., Louis, K., Bakkers, J., Melchers, W., Spanjaard, L., Wannet, W.J., Hoogkamp-Korstanje, M.A. 2006. Serotypes, geno types and antibiotic susceptibility profiles of group B streptococci causing neonatal sepsis and meningitisbefore and after introduction of antibiotic prophylaxis. Pediatr. Infect. Dis. J. 25, 945-948.

Moyo, S.R., Maeland, J.A., Bergh, K. 2002. Typing of human isolates of streptococcus agalactiae (group B streptococcus, gbs) strains from Zimbabwe. J. Med. Microbiol. 51, 595-600.

Ölçü, M., Eşel, D. 2007. Antibiotic susceptibilities of clinical streptococcus agalactiae isolates. J. Health Sci. 16, 23-27. 
Schrag, S.J., Phil, D., Zywicki, S. Farley, M.M., Reingold, A.L., Harrison, L.H., Lefkowitz, L.B., Hadler, J.L., Danila, R., Cieslak, P.R., Schuchat, A. 2000. Group B streptococcal disease in the era of intrapartum antibiotic prophylaxis. N. Engl. J. Med. 342, 15-20.

Topkaya, A., Küçükercan, M., Oğuzoğlu, N., Ünal, N., Narin, K. 2003. Antibiotic susceptibilities of group B streptococci isolated from vaginal and rectal colonization in pregnant women. J. Turk. Microbi. Society. 33, 242-245.

Tünger, A., Çavuşoğlu, C., Korkmaz, M. 2005. Group B streptococcus. Asya Microbi. 94-96.

Quiroga, M., Pegels, E., Oviedo, P., Pereyra, E., Vergara, M. 2008. Antibiotic susceptibility patterns and prevalence of group B streptococcus isolated from pregnant women in misiones, Argentina. Brazilian J. Microbi. 39, 245-25. 